\title{
Centesimal Series of Attenuation
}

National Cancer Institute

\section{Source}

National Cancer Institute. Centesimal Series of Attenuation. NCI Thesaurus. Code C88109.

Preparation of a homeopathic substance with a ratio of one part original material to 100 parts of carrier or solvent, traditionally lactose, water or ethanol. 